\title{
Motorbikes Automatic Module for Hand Brake and Fuel Cut Off Relay
}

\author{
Muhammad Firdaus Jauhari ${ }^{1{ }^{*}}$ Dwi Abdurahman ${ }^{1}$ Yuly Triono $^{1}$ \\ ${ }^{1}$ Automotive Mechanical Engineering, Politeknik Negeri Banjarmasin, 70124, Indonesia \\ ${ }^{*}$ Corresponding author.Email: firdaus.jauhari@poliban.ac.id
}

\begin{abstract}
Data on the number of motorbikes theft cases each year is quite high, this is related to the number of parties involved in the stolen vehicle business. To ensure the safety of motorbikes, the following research offers a module design that doubles as a hand brake and a fuel cut-off relay. The module works when the motorbike is parked using the Arduino Uno microcontroller to activate the actuator via a smartphone and normalizes the two functions when the motorbike is going to run. The power of the module uses a motorbike battery with a voltage of 7.5 volts, and the test results show that the module can work according to the specified design. If the motorbike is stopped and the ignition switch is turned off, the fuel cut-off relay will immediately turn off the injector, then the driver needs to pair the Android smartphone with the Arduino Uno microcontroller using the Boarduino application to activate the DC motor as a hand brake. Based on the tests carried out, the Bluetooth signal coverage distance can reach 15 meters. This research complements the types and ways of using Android smartphones and microcontrollers that are implemented as security devices for motorized vehicles to avoid crime.
\end{abstract}

Keywords: Motorbikes, Theft, Handbrake, Fuel Cut Off, Microcontroller.

\section{INTRODUCTION}

The number of motorized vehicles, especially motorbikes in urban areas, continues to increase every year Motorbikes are a choice of private transportation for most people, because of the affordable purchase prices and easy access to motorbikes. Unfortunately, based on BPS data [1], this is followed by a high number of crime statistics related to motorbikes theft, which is 27,731 cases in one year. In another report, it was stated that the large population of motorbikes opened up the opportunity to target motorbikes crime and robbery. The increasing demand for motorbikes has provided business opportunities for robbers, catchers, and sellers of stolen motorbikes [2].

In general, motorbikes theft is done by forcibly damaging the ignition key. The vandalism was carried out by using a T-shaped key or a lock equipped with a magnet to start a parked motorbike. There are many ways that we can use to avoid vehicle theft, one of which is using a Raspberry Pi microcontroller and an Android smartphone as a safety system. This system works when there is high vibration coming from a motorbike, the sensor will send vibrations to the raspberry pi microcontroller output and then send a warning message.
Vehicle owners can control a motorbikes engine via an Android smartphone [3]. In similar research, it is proposed to implement fingerprint-based ignition for motorbikes. In this way, the motorbike can only be started with a registered fingerprint, and an alarm will sound if the sensor fails to detect an unregistered fingerprint three times in a row [4]. Other research describes a dual security system for motorbikes that utilize GPS (Global Positioning System) and Bluetooth connection on an android smartphone [5]. In this system, the security features utilize Bluetooth communication to disconnect or connect the motorbikes ignition system, and GSM communication to stop the vehicle in a stolen situation. In another study, it was suggested that a security system works automatically when the ignition is turned off. The security features utilize touch key activation and Bluetooth communication which are used to control the main sensor signal as a condition for starting a motorbikes [6]. Another method used for additional vehicle security is to use IoT (Internet of Things) as a smart security system. This system uses a microcontroller that will send messages from the driver and the position of the vehicle coordinates to the police post and the operator in the event of a crime [7]. 
In this paper, the authors propose an additional security module for motorbikes to avoid theft. This module utilizes an Arduino microcontroller and a DC motor that functions as a hand brake and fuel cut-off relay, becoming a safety system for motorbikes. The system will be planted on the motorbike and integrated into the electrical system so that it can be used to prevent crime when the motorbike is parked.

\section{METHOD}

\subsection{Designing Hardware and Software}

The research design in this design is to use an experimental method, with the initial design stage identifying the equipment that will be needed in research such as the Arduino microcontroller as a control unit and running the program created. Arduino Uno is a microcontroller board that is fully controlled by the ATmega328. The Arduino Uno has 14 digital input or output pins, 6 analog inputs, a $16 \mathrm{MHz}$ crystal oscillator, a USB connection, a power jack, an ICSP header, and a reset button [8]. Other components are Bluetooth HC-06, Android Smartphone, DC Motor, Step Down Module, Relay Module, APK Boarduino, and DC Jack Power Male Connector. The design stage follows the control flow of the system that we propose can be seen in Figure 1. The point is that when the motorbikes is parked, the driver will activate the hand brake and the fuel cut off

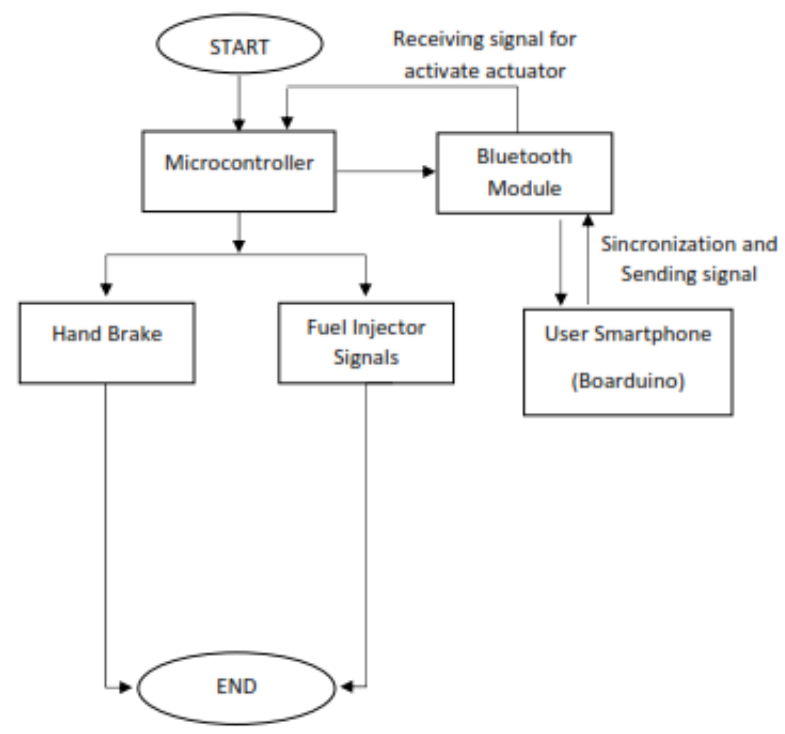

Figure 1 Control flow of the proposed system

In parking conditions, the driver can lock the front wheel of the motorbikes using the hand brake feature on the module, and automatically deactivates the fuel injector on the motorbike when the ignition is off (Figure 4). If the motorbike is to be run, the driver must release the hand brake so that the wheels are not locked and activate the fuel injectors so that fuel is injected into the engine relay so that the motorbikes is locked and the fuel cannot be injected into it. in the engine cylinder. Even if the ignition key was damaged manually, the motorbike could not walk and could not be turned on directly. It can be seen that the design of this module includes the hardware and software that will be used (Figure 2), then testing the prototype that has been completed. For software, the Arduino IDE is used because this program is an intermediary device between the Arduino compiler and the microcontroller to perform embedded functions through programming syntax. The Arduino IDE uses its programming language called Sketch, and changes have been made to make it easier for beginners to programming from the original language [9].

\subsection{Block Diagram Description}

The block diagram in Figure 3 below explains how the proposed automatic motorbikes module works. The power source for the module uses a 12-v battery from a motorbike, the $12-\mathrm{v}$ voltage is passed a step down so that it drops to $7 \mathrm{v}$. This is a safe working voltage range for the Arduino Uno microcontroller. The incoming $7 \mathrm{v}$ voltage will activate the Arduino Uno microcontroller, and turn on the Bluetooth module to synchronize the signal with an android smartphone. If the synchronization is successful, the driver can move the actuator by sending commands to the Arduino Uno microcontroller to activate the hand brake and fuel cut off functions.

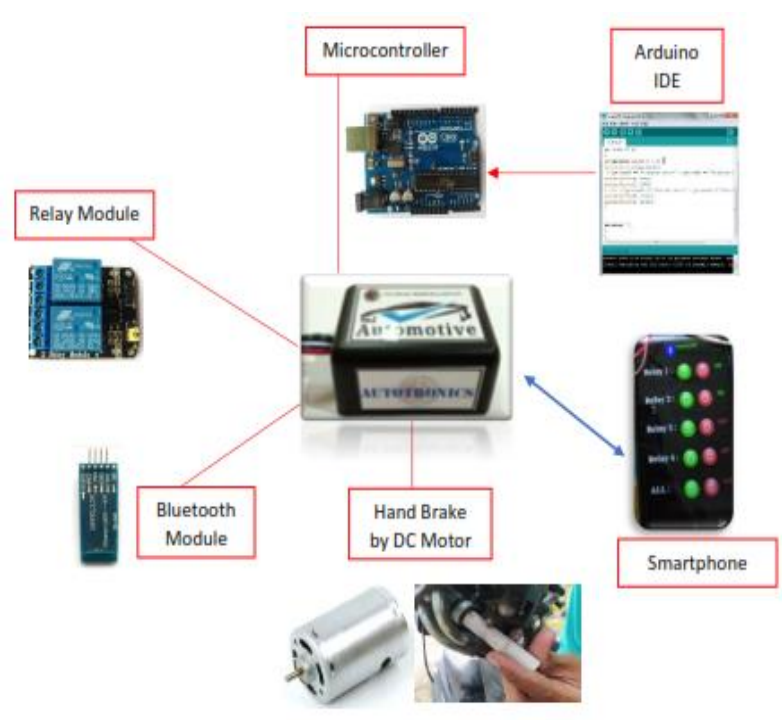

Figure 2 Embedded system architecture

cylinder. The signal sent from the Android smartphone to the Arduino Uno microcontroller uses the Boarduino application as in Figure 5, and the signal will be forwarded to the relay module component which functions as an actuator. 


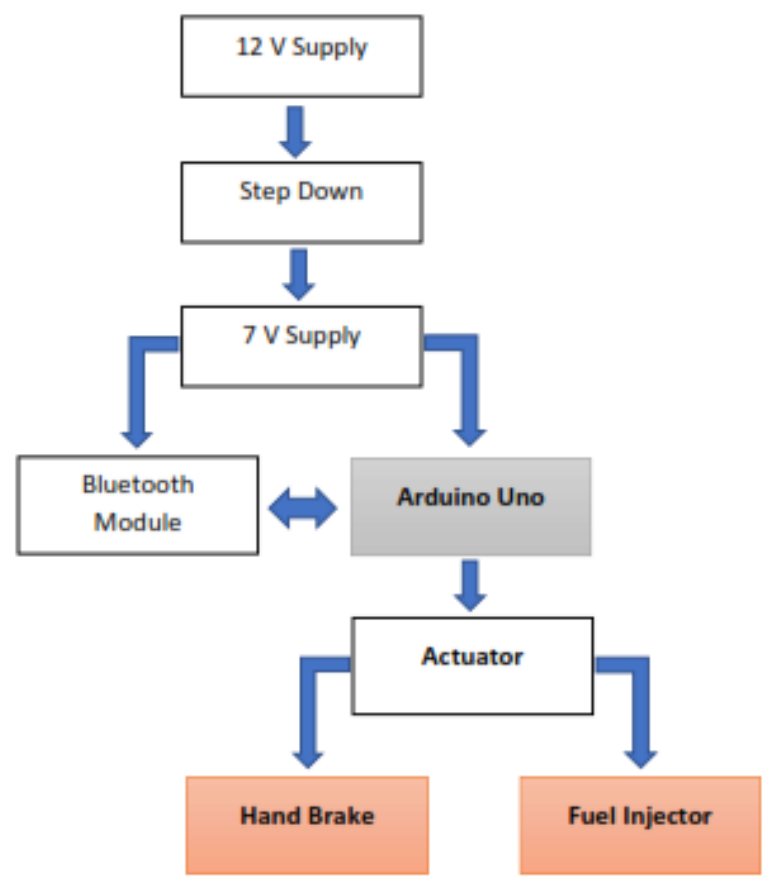

Figure 3 Block diagram of proposed system

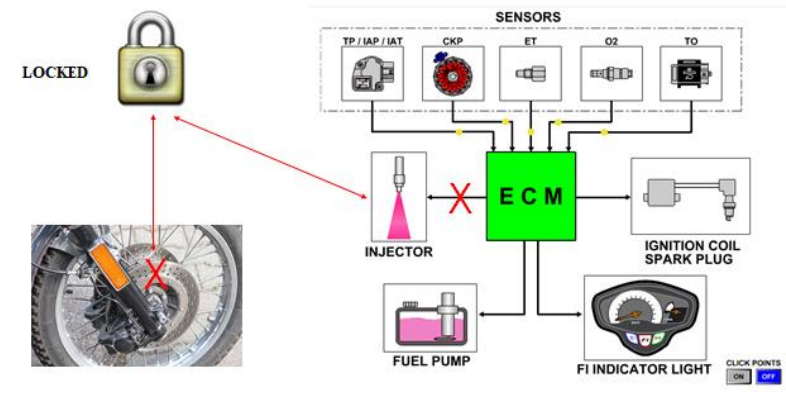

Figure 4 Locking of wheels and fuel injectors

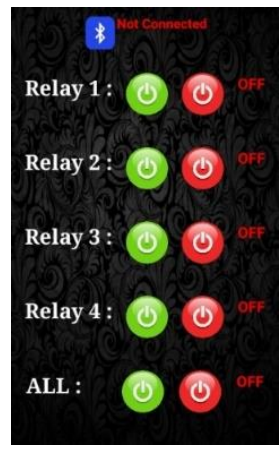

Figure 5 APK Boarduino

\section{RESULT AND DISCUSSION}

In this design, the automatic motorbikes module that has been made is implanted on the motorbike for the testing process. The module is made simple and concise, placed in the location under the motorbikes seat so that it is not visible and avoid the rain. A little modification is needed on the brake handle to install a DC motor component that has been given a shell so that it can function as a hand brake. You do this by adding a bolt whose length matches the end of the DC motor, this bolt will hold the movement of the brake handle later. The next step is to connect the fuel injector circuit to the module so that it can function as a fuel cut-off relay. The way it works, the fuel injector circuit will be disconnected automatically when the ignition is off, this makes there is no fuel injection into the engine cylinder and the motorbike cannot be started (Figure 6). The assembly process and module testing can be seen in Figure 7 below. At the top is the process of connecting the module to the fuel injector circuit, then installing a DC motor on the front wheel brake handle. While the bottom of the picture shows the testing process when the ignition switch is on, release the hand brake, fuel injector activation, and finally starting the motorbikes.

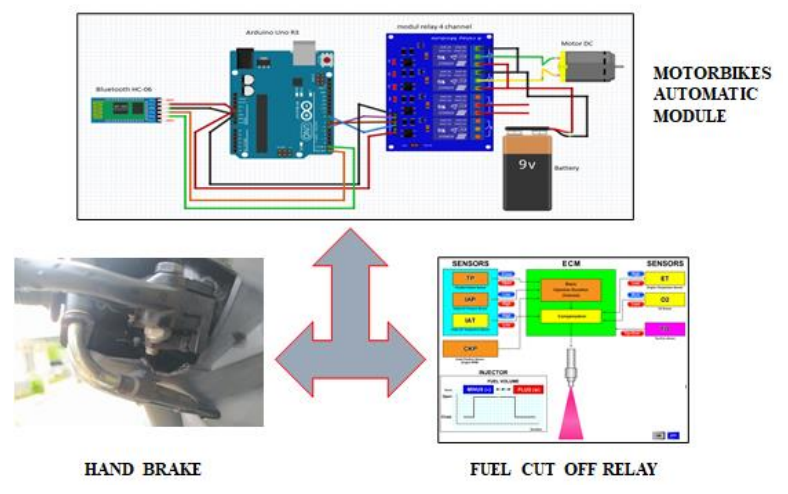

Figure 6 Automatic motorbikes module wiring

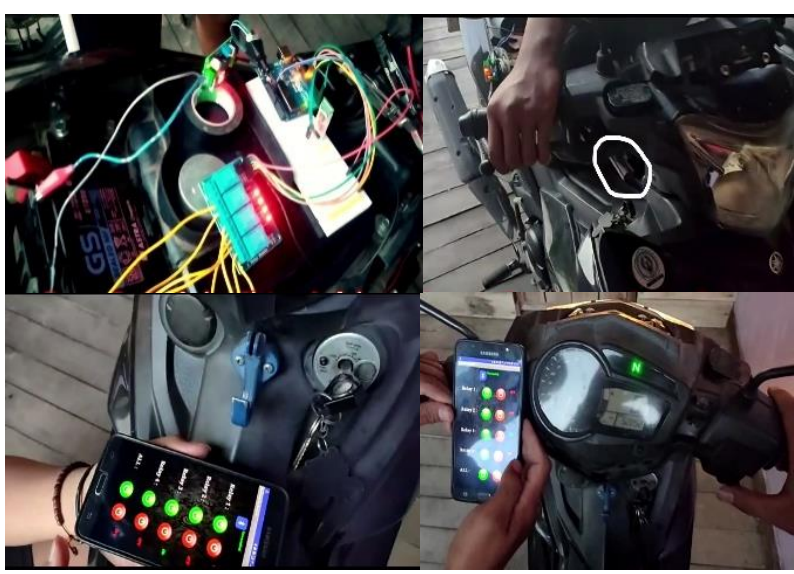

Figure 7 Module assembly and testing processes

For safety factors, the voltage that supplies the Arduino Uno microcontroller is maintained in the 7-9 Volt range. This is to avoid overheating conditions on the Arduino components and several other components that can cause damage. Voltage measurements are carried out using a multimeter before the step-down and after the step-down, and the results of the measurement can be seen in Table 1 below. 
Table 1. Voltage Measurement

\begin{tabular}{llc} 
Measurement & Variables & Voltage (Volt) \\
\hline$V_{\text {in }}$ (before step down) & Voltage & 12 \\
\hline$V_{\text {out }}($ after step down) & Voltage & 7,5 \\
\hline
\end{tabular}

The test results show the module can work according to the specified design. Because the module functions as an additional security system on a motorbike, the module is used when the motorbike is parked so that it can be avoided from vehicle theft. If the motorbikes are stopped and the ignition switch is turned off, the fuel cut-off relay will turn off the injectors immediately, this means that the fuel flow has been cut off. In the next step, the driver needs to pair the Android smartphone with the Arduino Uno microcontroller using the Boarduino application. The front brake handle is pulled for a moment and relay 1 (on) is activated, then the DC motor rotates and pushes forward the iron rod which will hold the brake handle and make it function as a hand brake. This condition prevents the front wheels from turning and the fuel flow from the tank to the engine cylinder is cut off.

At the time this module was made and tested on motorbikes, we had not made a manual switch as a shortcut for drivers in case of loss of smartphones or critical smartphone conditions because there is no charger. So that the use of this module is assumed to be in ideal conditions. However, in the next development, we have added a manual shortcut for the driver if the smartphone is lost or runs out of power, but the drawback only functions to normalize the fuel cut-off relay feature. As for the hand brake feature, there is no manual shortcut for the driver.

In addition to the voltage measurement, the measurement of the Bluetooth signal reception range between the android smartphone and the Bluetooth module is also carried out. Based on the tests carried out, the Bluetooth signal coverage distance reaches a distance of 15 meters. When the motorbike is to be used, the driver must press the relay button 2 (on) to release the brake handle and deactivate the hand brake. Next, reconnect the fuel injector circuit by pressing the relay button 3 (on) so that the electric current will activate the fuel injectors to work normally. The final step is to press the starter switch to start and run the motorbikes.

\section{CONCLUSION}

We can improve the safety of motorbikes from possible theft in many ways, one of which is using the Motorbikes Automatic Module which can function as a Hand Brake and Fuel Cut Off Relay during parking conditions. The module can prevent motorbike crimes that are generally committed in a short time by breaking the manual ignition switch and taking away the successfully started motorbikes. This research complements the types and ways of using Android smartphones and microcontrollers which are implemented as security devices for motorized vehicles so they can avoid crime

\section{ACKNOWLEDGMENTS}

We would like to thank the P3M Politeknik Negeri Banjarmasin for the support of the publication, also to fellow technicians and students of the Automotive Mechanical Engineering Department who have helped a lot in this project

\section{REFERENCES}

[1] BPS, "Statistik Kriminal 2019," 2019, doi: 04330.1903.

[2] E. Andina, "STUDI KASUS BEGAL SEPEDA MOTOR DI KOTA DEPOK Juvenile' s Violent Crime : Case Study of Violent Motorbikes Theft in Depok City," no. November, 2015.

[3] D. E. Kurniawan and M. N. Surur, "Perancangan Sistem Pengamanan Sepeda Motor Menggunakan Mikrokontroler Raspberry Pi dan," vol. 2, no. 2, pp. 93-104, 2016.

[4] H. Supriyono, A. A. Wijayanto, R. Jailani, and M. O. Tokhi, "Design, Implementation, and Evaluation of a Fingerprint-Based Ignition Key for Motorbikess," Automot. Exp., vol. 3, no. 2, pp. 68 80, 2020, doi: https://doi.org/10.31603/ae.v3i2.3586.

[5] O. K. Saputra and Herlinawati, "Rancang Bangun Sistem Keamanan Kendaraan Bermotor Berbasis GPS ( Global Positioning System ) dan Koneksi Bluetooth," Rekayasa dan Teknol. Elektro, vol. 11, no. 3, p. 9, 2017.

[6] M. M. A. M F Jauhari, "The development of appropriate technology: Simple double layer vehicle safety system," J. Phys. Conf. Ser., vol. 1450 , p. 012103 , 2020, doi: 10.1088/17426596/1450/1/012103.

[7] I. Indrianto, M. N. I. Susanti, R. R. A. Siregar, P. P. J., and Y. Purwanto, "Smart taxi security system design with internet of things (IoT)," TELKOMNIKA (Telecommunication Comput. Electron. Control., vol. 17, no. 3, p. 1250, 2019, doi: 10.12928/telkomnika.v17i3.10167.

[8] A. Kadir, Pemrograman Arduino dan Processing, 1st ed. Elex Media Komputindo, 2017.

[9] M. Banzi and M. Shiloh, Make: Getting started with Arduino. 2014. 